\title{
Effect of the Wnt1/ $\beta$-catenin signalling pathway on human embryonic pulmonary fibroblasts
}

\author{
PING SONG ${ }^{1}$, JIN-XU ZHENG ${ }^{1}$, JI-ZHU LIU ${ }^{2}$, JIAO XU ${ }^{1}$, LI-YAN WU ${ }^{1}$, CHAO LIU $^{1}$, QIN ZHU ${ }^{1}$ and YANG WANG ${ }^{1}$ \\ ${ }^{1}$ Respiratory Department, Affiliated Hospital of Jiangsu University, Zhenjiang, Jiangsu 212001; \\ ${ }^{2}$ Respiratory Department, Huaibei Miner General Hospital, Huaibei, Anhui 235000, P.R. China
}

Received July 31, 2013; Accepted March 4, 2014

DOI: $10.3892 / \mathrm{mmr} .2014 .2261$

\begin{abstract}
Idiopathic pulmonary fibrosis (IPF) is a fibrotic lung disease associated with a high rate of mortality, characterised by an accumulation of fibroblasts/myofibroblasts in the fibroblastic foci (FF) and by an excessive deposition of extracellular matrix (ECM) in the lung parenchyma. The pathogenesis of this fatal disorder remains unclear. Previous evidence suggests that myofibroblasts are key effectors of the deposition of ECM. In the present study, human embryonic pulmonary fibroblast (HEPF) cells were incubated with different concentrations of Wnt1. The present study revealed that cell proliferation improved following stimulation using different concentrations of Wnt1 in a concentration-dependent manner. When the concentration exceeded $20 \mu \mathrm{g} / 1$, cell proliferation was significant $(\mathrm{P}<0.05)$ and the cell expression of $\alpha$-SMA, vimentin and collagen I mRNA, as well as protein expression, significantly increased $(\mathrm{P}<0.05)$. Bronchoalveolar lavage fluid (BALF) was then obtained from bleomycin (BLM)-induced models of pulmonary fibrosis. HEPF cells were cultured with Dulbecco's modified Eagle's medium plus BALF. The mRNA and protein expression of $\alpha$-SMA, vimentin and collagen I significantly increased and these increases were associated with $\beta$-catenin. Furthermore, following being infected with the lentivirus expressing $\beta$-catenin shRNA, HEPF cells were cultured with BALF. However, the mRNA and protein expression of $\alpha$-SMA, vimentin and collagen I did not increase significantly. The present study suggested that the Wnt1/ $\beta$-catenin signalling pathway can promote HEPF cell proliferation and induced HEPF cells can change into myofibroblasts and promote ECM deposition. These findings may provide a theoretical basis for the treatment of IPF.
\end{abstract}

Correspondence to: Professor Jin-Xu Zheng, Respiratory Department, Affiliated Hospital of Jiangsu University, 438 Jiefang Road, Zhenjiang, Jiangsu 212001, P.R. China

E-mail: jinxuzheng@126.com

Key words: fibroblast, wnt1, $\beta$-catenin, pulmonary fibrosis

\section{Introduction}

Idiopathic pulmonary fibrosis (IPF) is a progressive disease of unknown etiology associated with a high rate of mortality. The histology of IPF demonstrates the features of usual interstitial pneumonia with a patchy distribution of fibrosis adjacent to fibroblastic foci (FF) (1). FF are composed of migrating and proliferating fibroblasts and myofibroblasts accounting for extracellular matrix (ECM) deposition. This excessive and uncontrolled deposition of ECM compromises normal lung function and structure $(2,3)$. Myofibroblasts are a key factor in organ fibrosis and are characterised by the expression of $\alpha$-smooth muscle actin ( $\alpha$-SMA) (4). The pathogenesis of IPF is unknown and the role of inflammation remains controversial as anti-inflammatory treatment does not produce significant beneficial effects against the progression of the disease (5). Eventually, fibrosis self-maintains and progresses by an unknown process. Several studies have indicated that IPF is the result of injury to the alveolar epithelium that leads to a cascade of dysregulated epithelial-fibroblast crosstalk and abnormal wound healing $(6,7)$. In this model, through the release of growth factors and cytokines, epithelial injury leads to the excessive proliferation of fibroblasts, transformation of fibroblasts to myofibroblasts and ECM deposition culminating in parenchymal destruction $(6,8)$. Previous studies indicated that the Wnt signalling pathway is active in pulmonary interstitial fibrosis and other fibrous proliferative diseases $(9,10)$. Königshoff et al found that the mRNA expression and immunohistochemical reactivity of Wnts 1 and 3a increase in adjacent pulmonary epithelium in IPF patients (11). However, the signalling pathways involved are not completely understood. The current study investigated Wntl stimulation of human embryonic lung fibroblasts, the transition of human embryonic pulmonary fibroblasts (HEPF) to myofibroblasts, as well as the synthesis, function and proliferation of the ECM. Furthermore, bronchoalveolar lavage fluid (BALF) obtained from fibrosis mouse model cultured HEPF cells were used to observe if this fluid was able to induce fibrosis transition to microfibrosis, as well as its association with the Wnt/ß-catenin signalling pathway. Furthermore, after the lentivirus containing $\beta$-catenin shRNA knocked-out the $\beta$-catenin gene, HEPF cells were cultured with BALF to observe whether HEPF microfibrosis transformation was affected. The present study investigated Wnt signalling in lung fibre formation to 
determine the possible mechanism of this formation and to provide a theoretical basis for IPF-targeted therapy.

\section{Materials and methods}

Cell culture. HEPF cells were provided by the Institute of Biochemistry and Cell Biology (Shanghai Institute of Biological Science, Chinese Academy of Sciences, Shanghai, China) and were cultured with Dulbecco's modified Eagle's medium (DMEM; Sunshine Biotechnology Co., Ltd., Nanjing, Jiangsu, China) supplemented with $10 \%$ foetal bovine serum (FBS; Invitrogen Life Technologies, Carlsbad, $\mathrm{CA}, \mathrm{USA}$ ) at $37^{\circ} \mathrm{C}$ in a $5 \% \mathrm{CO}_{2}$ and $95 \%$ air incubator.

Animal treatments. We used 6- to 8-week old (18 \pm 2 g) SPF female C57BL/6 mice (Laboratory Animal Center of Jiangsu University, Zhenjiang, Jiangsu, China). The mice had free access to water and rodent laboratory chow. A group of mice were injected intratracheally with $5 \mathrm{mg} / \mathrm{kg}$ of bleomycin (BLM) solutions (Nippon Kayaku Co., Ltd., Tokyo, Japan) and the control group received the same volume of saline, as previously described (12-14). On day 7 post-modelling, mice were sacrificed by cervical dislocation and bronchoalveolar lavage (BAL) was performed. Following excision of the trachea, a plastic cannula was inserted into the trachea and $1.0 \mathrm{ml}$ of saline solution was gently injected using a syringe and then withdrawn. This procedure was repeated three times. Then BALF was centrifuged at $716 \mathrm{x} g$ for $5 \mathrm{~min}$. The supernatants were preserved at $-70^{\circ} \mathrm{C}$ and the lung tissues were harvested. The animal use protocol was reviewed and approved by the Institutional Animal Care and Use Committee of Jiangsu University (Zhenjiang, Jiangsu, China). This study was approved by the Laboratory Animal Management Committee of Jiangsu University.

$H \& E$ staining. On day 7 post-modelling, mice were sacrificed. The left lung was rinsed in PBS, fixed in $4 \%$ paraformaldehyde (Sunshine Biotechnology Co., Ltd.) for $24 \mathrm{~h}$, embedded in paraffin and cut into $5 \mu \mathrm{m}$ sections. The slides were stained with $\mathrm{H} \& \mathrm{E}$ for cell alignment to evaluate the degree of inflammation.

Methylthiazoltetrazolium (MTT) assay. The day prior to the experiment, HEPF cells were diluted to $1 \times 10^{4}$ cells $/ \mathrm{ml}$ and seeded in 96-well culture plates, with $100 \mu \mathrm{l}$ in each well. After HEPF cells were cultured to 60-70\% confluence, HEPF cells were placed in a serum-free DMEM medium $24 \mathrm{~h}$ prior to treatment. Following that, the cells were grouped randomly. The blank group consisted of serum-free DMEM in wells without cells and the experimental groups were exposed to DMEM plus $10 \%$ FBS containing various concentrations of Wnt1 (0, 5, 10, 20, 40 and $80 \mu \mathrm{g} / \mathrm{l}$ ) (Peprotech, Rocky Hill, NJ, USA) for $48 \mathrm{~h}$. Following the experimental periods, $20 \mu \mathrm{l}$ of MTT ( $5 \mathrm{mg} / \mathrm{ml}$; Amresco Inc., Solon, OH, USA) was added to each well and the plates were incubated for another $4 \mathrm{~h}$ at $37^{\circ} \mathrm{C}$ in a humidified $5 \% \mathrm{CO}_{2}$ atmosphere. The supernatant was then discarded and $150 \mu 1$ of dimethylsulfoxide (DMSO; Sigma, St. Louis, MO, USA) was added to each well. The optical density (OD) was measured with a microplate reader (SpectraMax 340; Molecular Devices Corp., Sunnyvale, CA,
USA) at a wavelength of $570 \mathrm{~nm}$. The proliferation rate was calculated using the equation: Proliferation rate $(\%)=\mathrm{Ab}_{570}$ treated $/ \mathrm{Ab}_{570}$ control x $100 \%$.

Immunofluorescence. HEPF cells were seeded in a 24-well plate and slides at a density of $1 \times 10^{3}$ cells per well, following being synchronously cultured in DMEM serum-free medium for $24 \mathrm{~h}$ and then in $10 \%$ FBS containing Wnt 1 at a concentration of $20 \mu \mathrm{g} / \mathrm{l}$ for $48 \mathrm{~h}$. Following the experimental treatment, HEPF cells were fixed with $4 \%$ paraformaldehyde for $15 \mathrm{~min}$. The cells were permeabilised for 8 min with $0.5 \%$ Triton X-100 (BD Biosciences) in PBS, then inhibited in PBS supplemented with $1 \%$ BSA (BD Biosciences, Shanghai, China) for $1 \mathrm{~h}$ and incubated overnight at $4^{\circ} \mathrm{C}$ with $1: 100$ rabbit anti- $\beta$-catenin antibody (Cell Signaling Technology, Inc., Danvers, MA, USA). The cells were washed for $20 \mathrm{~min}$, incubated with secondary antibody (1:100 goat anti-rabbit; labelled with cy3; Boster Biological Technology, Wuhan, Hubei, China) for $1 \mathrm{~h}$ at $37^{\circ} \mathrm{C}$ and then stained with Hoechst $(10 \mu \mathrm{g} / \mathrm{ml}$ in PBS $)$ for $20 \mathrm{~min}$. The cells were finally mounted on glass slides and observed using fluorescence microscopy (BX-51; Olympus, Tokyo, Japan).

Western blot analysis. Total proteins were extracted after the cells were collected, then separated using SDS-PAGE (Sunshine Biotechnology Co., Ltd.) and transferred onto polyvinylidene difluoride membranes. The membranes were inhibited with skimmed milk powder and then probed for proteins of interest. These membranes were probed using mouse anti-human antibody against $\alpha$-SMA, vimentin and $\beta$-actin (Santa Cruz Biotechnology, Inc., Santa Cruz, CA, USA) or rabbit anti-human collagen I (Santa Cruz Biotechnology, Inc.) and $\beta$-catenin. The primary antibodies were used in the following concentrations: anti- $\beta$-actin, 1:1,000; anti-SMA, 1:200 and anti-collagen I, 1:1,000. The horseradish peroxidase-goat anti-rabbit and anti-mouse secondary antibodies (Santa Cruz Biotechnology, Inc.) concentrations were 1:5,000. ECL detection reagents were used for visualisation (Amersham Biosciences, Piscataway, NJ, USA). The band densities for each phenotype marker were quantified using Lane 1D software (Beijing Sage Creation Science And Technology Co., Ltd., Beijing, China) following scanning with a GS-710 calibrated imaging densitometer ChampChemi basic (Bio-Rad, Hercules, CA, USA). The results were expressed as a ratio of band density to total $\beta$-actin.

Real-time polymerase chain reaction (RT-PCR). RT-PCR was used to determine the mRNA expression of $\alpha$-SMA, vimentin, collagen I and $\beta$-catenin. Total RNA was isolated using TRIzol reagent (Invitrogen Life Technologies) and cDNAs were generated using a PrimeScript RT reagent kit (Takara, Dalian, China) at $37^{\circ} \mathrm{C}$ for $15 \mathrm{~min}$ and then at $85^{\circ} \mathrm{C}$ for $5 \mathrm{sec}$. The specific primers for the PCR reaction were as follows: $\alpha-S M A$, forward 5'-TCAAATACCCCATTGAACACGG-3' and reverse 5'-GGTGCTCTTCAGGTGCTACA-3' with a product size of 178 bp; vimentin, forward 5'-TGCGTGAAATGGAAGAGA ACT-3' and reverse 5'-TCAGGTTCAGGGAGGAAAAGT-3' with a product size of $240 \mathrm{bp}$; collagen I, forward 5'-TCTGACTGGAAGAGTGGAGAGTAC-3' and reverse 5'-ATCCATCGGTCATGCTCTCG-3' with a product size of 
$202 \mathrm{bp} ; \beta$-catenin, forward 5'-GCTACTCAAGCTGATTTG ATGGA-3' and reverse 5'-GGTAGTGGCACCAGAATGG ATT-3' with a product size of $120 \mathrm{bp}$; GAPDH, forward 5'-GGATTTGGTCGTATTGGG-3' and reverse 5'-GGAAGA TGGTGATGGGATT-3' with a product size of $205 \mathrm{bp}$. Quantitative PCR was performed using the Mx3000P qPCR System (Stratagene, La Jolla, CA, USA) with SYBR Premix Ex Taq (Takara). A total of $1 \mu l$ of reverse transcription reaction mixture was utilised for a quantitative PCR in a total volume of $20 \mu \mathrm{l}$. The PCR cycles were $95^{\circ} \mathrm{C}$ for $30 \mathrm{sec}$ followed by 40 cycles of $95^{\circ} \mathrm{C}$ for $5 \mathrm{sec}$ and $58^{\circ} \mathrm{C}$ for $30 \mathrm{sec}$. Data were analysed according to the comparative $\mathrm{Ct}$ method and then normalised to GAPDH expression levels within each sample. The relative expression levels of target genes, following normalisation to an endogenous sequence, were given by $2^{-\Delta \Delta C t}$.

Statistical analysis. Statistical analysis was performed using a statistical software package (SPSS for Windows version 16.0; SPSS, Chicago, IL, USA). Data are presented as the mean \pm standard deviation (SD). Statistical comparisons between the groups were performed using a two-tailed unpaired t-test or a one-way analysis of variance (AVOVA) followed by a SNK-q test for studies with more than two groups. The Pearson's correlation analysis was also adopted. $\mathrm{P}<0.05$ was considered to indicate a statistically significant difference.

\section{Results}

Proliferation of HEPF cells. An MTT assay revealed that the OD of HEPF cells in the experimental groups were higher than that of the control group following $48 \mathrm{~h}$ of treatment. When the concentration exceeded $20 \mu \mathrm{g} / \mathrm{l}$, the OD significantly increased $(\mathrm{P}<0.05$; Fig. 1A). The present study indicated that Wnt1 was able to induce the proliferation of HEPF cells and that this proliferation was concentration dependent.

Wnt1 stimulates SMA, vimentin and collagen I mRNA and protein expression. Western blot analysis and qRT-PCR revealed that SMA vimentin and collagen I mRNA and protein expression, increased in a concentration-dependent manner following the stimulation of HEPF cells with various concentrations of Wnt1 $(0,5,10,20$ and $40 \mu \mathrm{g} / \mathrm{l})$ for $48 \mathrm{~h}$. When the concentration of Wnt 1 exceeded $20 \mu \mathrm{g} / 1$, this expression significantly increased in the experimental group compared with the control group $(\mathrm{P}<0.05$; Fig. 1B). Following the stimulation of HEPF cells with Wnt1, $\beta$-catenin was mostly distributed in the nucleus as demonstrated by immunofluorescence (Fig. $1 \mathrm{Ca}-\mathrm{Cc}$ ). However, in the control cells, $\beta$-catenin was associated with the cell membrane in regions of cell-cell contact (Fig. 1Cd-Cf).

Histopathological changes. At present, the most widely used experimental model of lung fibrosis is the BLM-induced model. In the present study, BALF from BLM-induced models of pulmonary fibrosis on day 7 were obtained along with simultaneous mouse lung biopsy. In the sections stained with $\mathrm{H} \& \mathrm{E}$, we observed massive inflammatory cells and erythrocytes in the septum and alveoli, which were accompanied by fibroblast proliferation (Fig. 2B), unlike in the control group
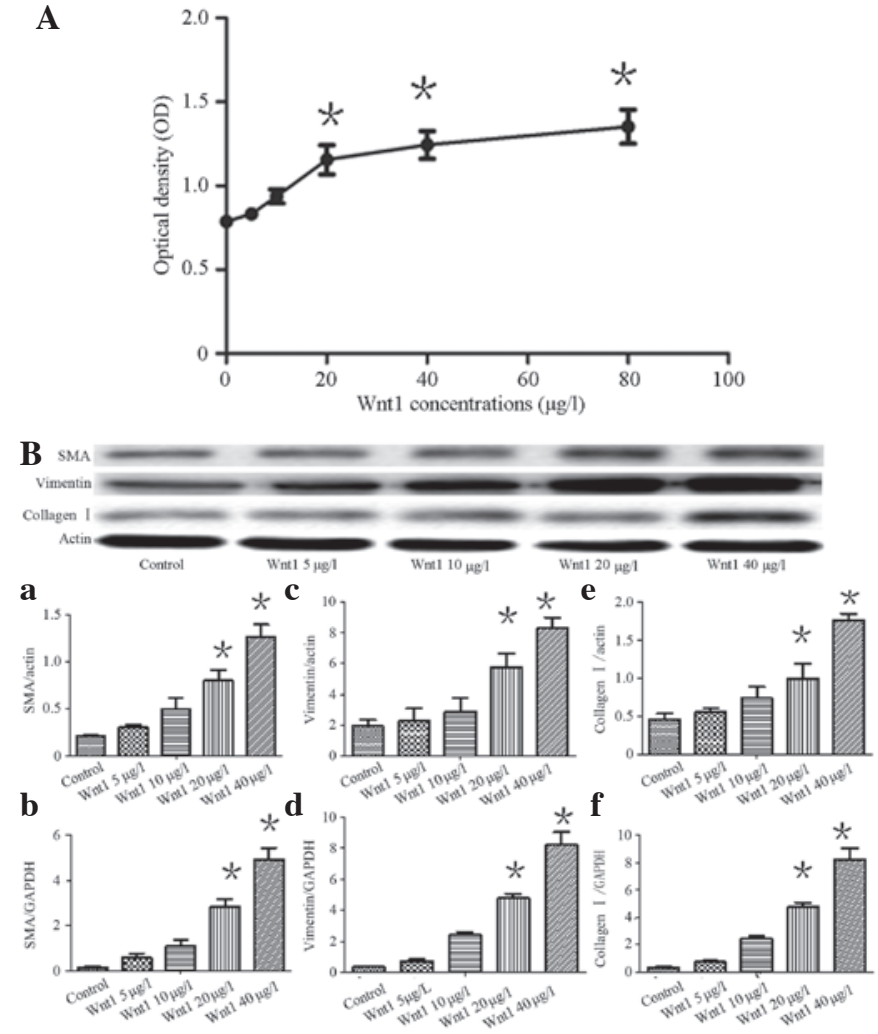

C
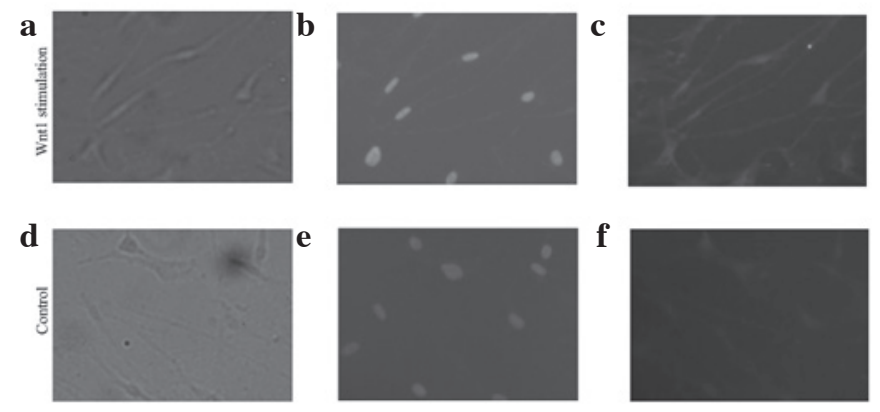

Figure 1. (A) Effects on cell proliferation stimulated by Wnt1, detected by MTT assay. Wnt1 was able to induce HEPF cell proliferation in a concentration-dependent manner. When the concentration was $>20 \mu \mathrm{g} / 1$, Wnt1 was able to markedly increase proliferation compared with the control group ( $\mathrm{P}<0.05$ ). (B) Effects of Wnt1 on the expression of $\alpha$-SMA, vimentin and collagen I in HEPF cells. (Ba) Western blot analysis demonstrating SMA protein expression. (Bb) qRT-PCR demonstrated SMA mRNA expression. $(\mathrm{Bc})$ Vimentin protein is shown. $(\mathrm{Bd})$ Vimentin mRNA was expressed. (Be) Expression of collagen I protein. (Bf) qRT-PCR for collagen I mRNA. From left: medium treated as the control group, various concentrations of Wnt 1 5, 10, 20 and $40 \mu \mathrm{g} / 1$. Each bar represents the mean $\pm \mathrm{SD}$; $\mathrm{P}<0.05$, versus the control. (Ca and d) HEPF cells were observed under a light microscope. ( $\mathrm{Cb}$ and e) Hoechst staining demonstrated cell nuclei under fluorescence microscopy. (Cc) HEPF cells stimulated with Wnt1 demonstrated $\beta$-catenin protein expression mostly localized in the nucleus. (Cf) In the controls, the $\beta$-catenin protein was expressed in the membrane (magnification, $\mathrm{x} 200$ ). HEPF, human embryonic pulmonary fibroblast; $\alpha$-SMA, $\alpha$-smooth muscle actin; MTT, methylthiazoltetrazolium; qRT-PCR, quantitative real-time polymerase chain reaction.

(Fig. 2A), which was given the same volume of saline. These results demonstrated that BLM-induced models of pulmonary fibrosis were constructed successfully.

BALF induces $\alpha$-SMA, vimentin and collagen I expression. To determine whether lung alveolar epithelial cell injury 

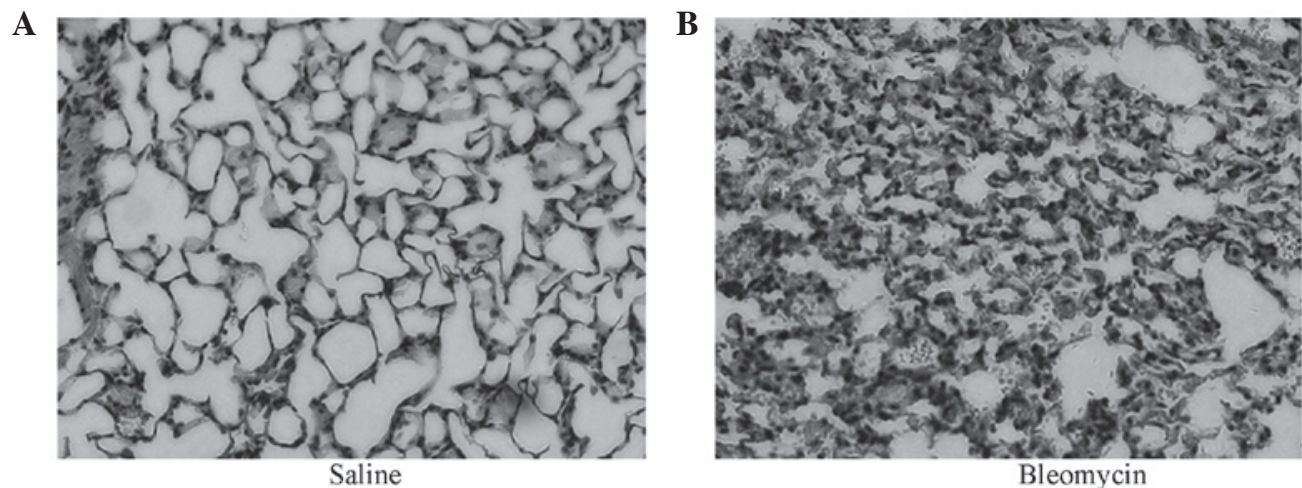

Figure 2. Histopathological changes in the lung tissues by the BLM-induced model. (A) Architectures of lung tissues in the control group were normal without clear inflammatory cells and collagen fibre proliferation. (B) On day 7 of the BLM group, the alveolitis reached culmination, with large inflammatory cells and erythrocytes in the septum and alveolus, accompanied by fibroblast proliferation. BLM, bleomycin.
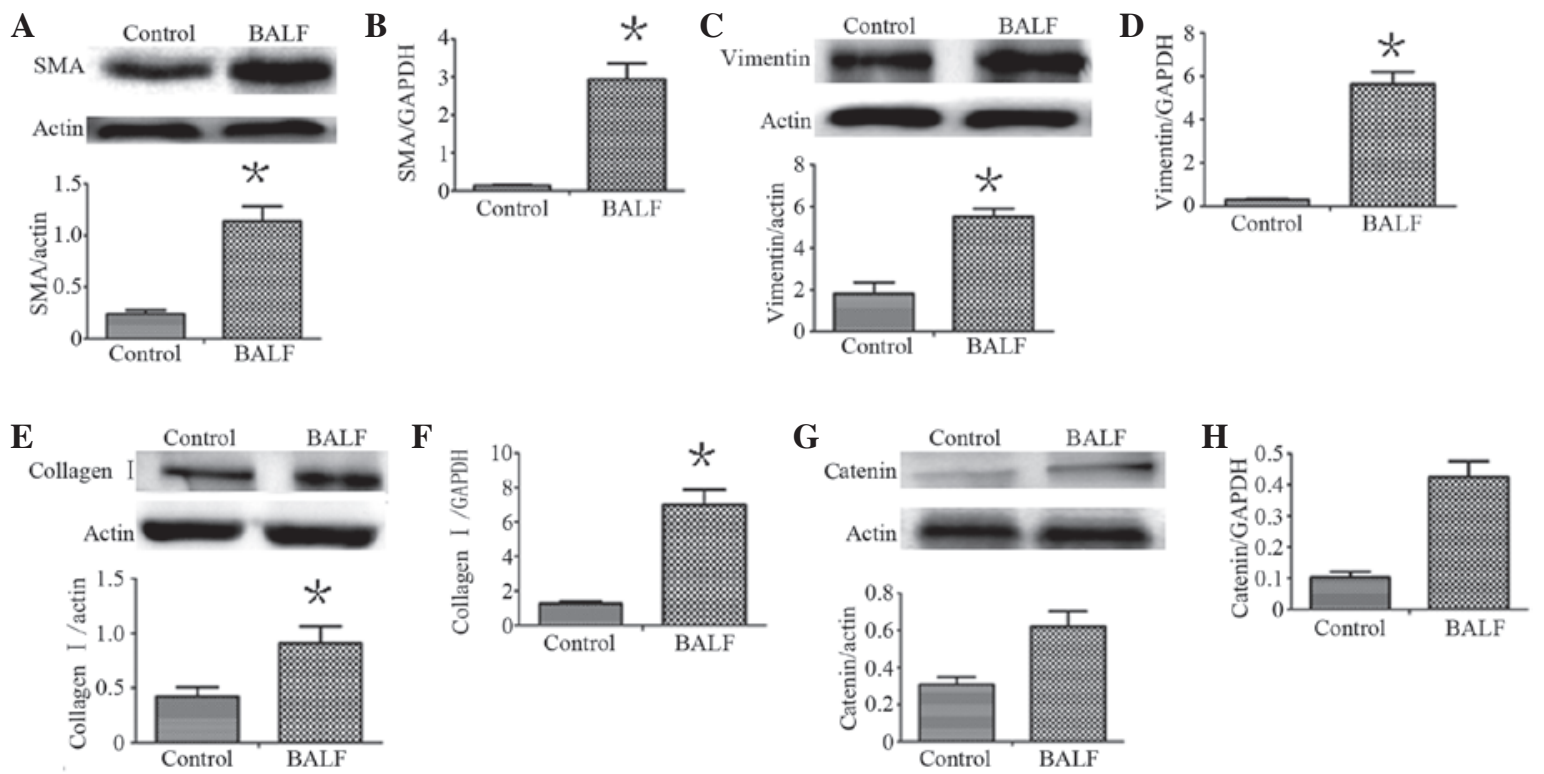

Figure 3. Expression of $\alpha$-SMA, vimentin and collagen I in HEPF cells cultured with BALF. (A, C and E) Western blot analysis demonstrating SMA, vimentin and collagen I protein expression; (B, D and F) qRT-PCR demonstrated SMA, vimentin and collagen I mRNA expression; (G and H) Western blot analysis and qRT-PCR demonstrated the expression of the $\beta$-catenin protein and mRNA. Expression of $\alpha$-SMA, vimentin and collagen I associated with the expression of $\beta$-catenin. Each bar represents the mean $\pm \mathrm{SD}$; ${ }^{*} \mathrm{P}<0.05$, compared with the control. HEPF, human embryonic pulmonary fibroblast; $\alpha$-SMA, $\alpha$-smooth muscle actin; BALF, bronchoalveolar lavage fluid; qRT-PCR, quantitative real-time polymerase chain reaction; SD, standard deviation.

induces fibroblast activation and ECM deposition, we used BALF obtained from BLM-induced models of pulmonary fibrosis on day 7 to culture HEPF cells. Using western blot analysis and real-time RT-PCR, HEPF cells exposed to BALF overexpressed $\alpha$-SMA, vimentin and collagen I compared with the control $(\mathrm{P}<0.05)$, as shown in Fig. 3. Whether these changes were associated with the Wnt signalling pathway was evaluated. $\beta$-catenin mRNA and protein was simultaneously detected. The increase in $\alpha$-SMA mRNA and protein was associated with $\beta$-catenin levels $(r=0.829,0.842)$. The increase in vimentin mRNA and protein was associated with $\beta$-catenin levels $(r=0.867,0.837)$ and the increase in collagen I mRNA and protein was associated with $\beta$-catenin levels $(r=0.817,0.881)$. Furthermore, we knocked down the $\beta$-catenin gene in the HEPF cells by infecting them with the lentivirus (sh $\beta$-catenin). Following $96 \mathrm{~h}$, unlike the untreated cells (Fig. 4Ad), the cells treated with lentiviruses expressing
GFP (Fig. 4Ab) indicated a successful infection. Western blot analysis demonstrated that the $\beta$-catenin levels in HEPF siRNA-infected cells were significantly lower than in cells infected with pLL-shNC (control siRNA; Fig. 4Ba and 4Bb). The qRT-PCR demonstrated the same result (Fig. 4Bc). The cells were cultured using BALF. Notably, as shown in Fig. 4C, compared with the shNC-infected cells, siRNA improved the expression of the $\alpha$-SMA, vimentin and collagen I of sh $\beta$-catenin-infected HEPF cells, which were induced by BALF (Fig. 4C).

\section{Discussion}

IPF is characterised by fibroblast/myofibroblast activation, ECM deposition and alveolar epithelial type II cell dysfunction, which all lead to parenchymal destruction. However, the origins of these characteristics remain to be elucidated. Recently, 
$\mathbf{A}$
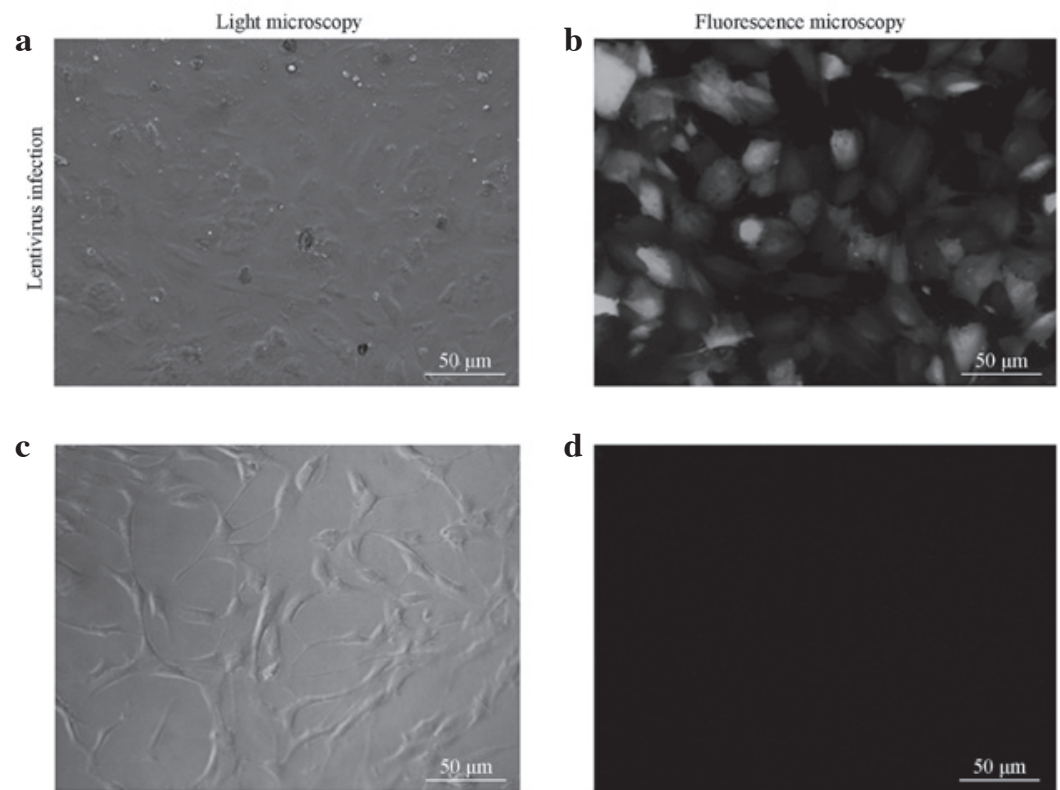

B
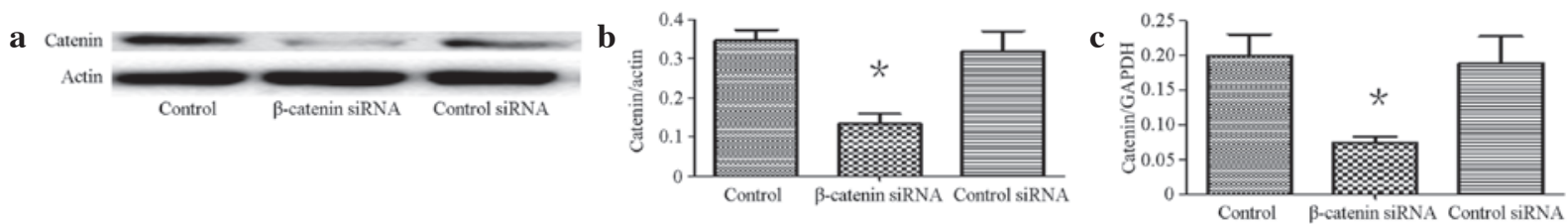

C

a

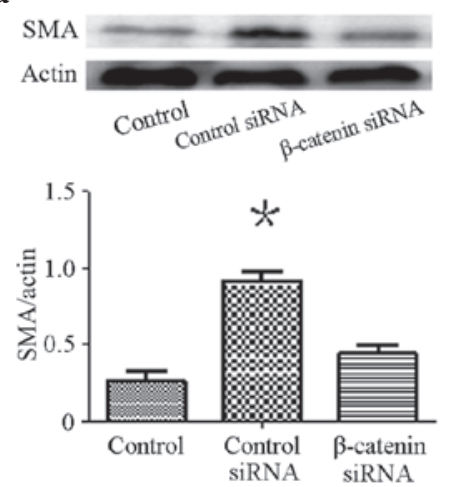

d

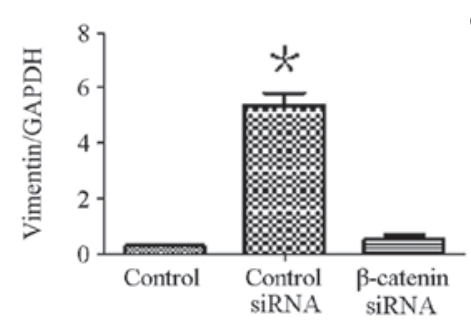

b

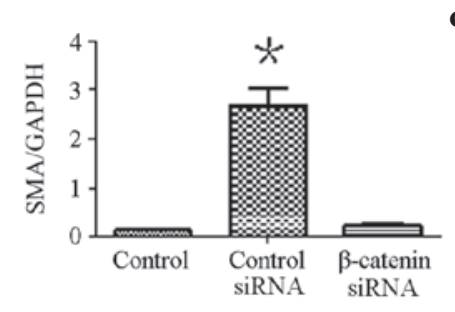

C

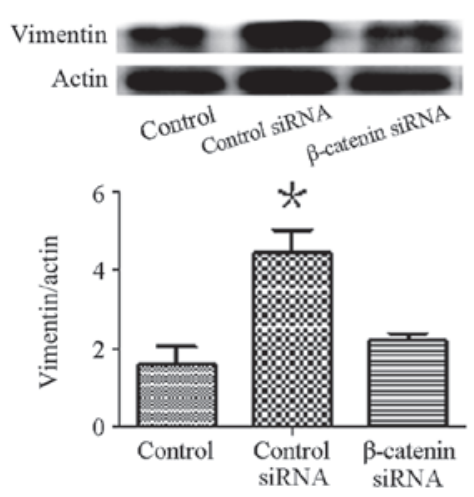

e
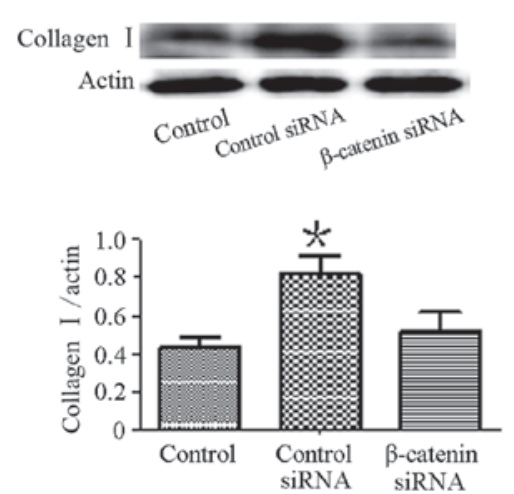

f

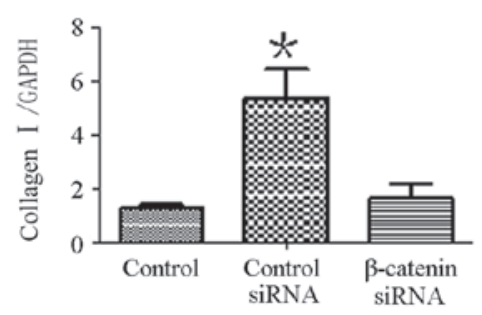

Figure 4. (A) HEPF cells observation results. (Aa and Ac) HEPF cells observed under light microscope. (Ab) GFP fluorescence (right panel) of HEPF cells observed under fluorescence microscopy (magnification, x200) $96 \mathrm{~h}$ after infection with the lentivirus containing pLL-sh catenin or shNC. (Ad) GFP fluorescence cannot be observed when the cells were not infected with the lentivirus. (B) Expression of $\beta$-catenin in HEPF cells infected with the lentivirus (sh $\beta$-catenin). Western blot analysis and qRT-PCR assessment that $\beta$-catenin siRNA suppresses $\beta$-catenin protein $(\mathrm{Ba}$ and $\mathrm{Bb})$ and $(\mathrm{Bc}) \mathrm{mRNA}$ expression in HEPF cells. Each bar represents the mean $\pm \mathrm{SD}$; " $\mathrm{P}<0.05$ compared with the control. (C) Effects of $\beta$-catenin siRNA attenuated HEPF cell differentiation into myofibroblasts. (Ca, Cc and Ce) Western blot analysis demonstratd $\alpha$-SMA, vimentin and collagen I protein expression; (Cb, Cd and Cf) qRT-PCR demonstrated $\alpha$-SMA, vimentin and collagen I mRNA expression. From left: medium-treated HEPF cells, $\beta$-catenin siRNA-treated BALF-treated cells and control siRNA-treated BALF-treated cells. Each bar represents the mean $\pm \mathrm{SD}, \mathrm{P}<0.05$. HEPF, human embryonic pulmonary fibroblast; $\alpha$-SMA, $\alpha$-smooth muscle actin; BALF, bronchoalveolar lavage fluid; qRT-PCR, quantitative real-time polymerase chain reaction; SD, standard deviation. 
a new hypothesis has been proposed based on the evidence that injury is key to the irreversible process of fibrosis and tissue remodelling. However, the molecular pathways linking injury with the development of fibrosis are poorly understood. Previous studies demonstrated that the Wnt signalling pathway is abnormally activated in lung fibrosis $(10,15-17)$. Classical Wnt signalling is initiated by extracellular ligands known as Wnts, including Wnt1 and Wnt3. In the absence of ligands, $\beta$-catenin is phosphorylated on a serine residue by glycogen synthase kinase- $3 \beta$ (GSK-3 $\beta$ ) in a complex that includes adenomatous polyposis coli and axin. Phosphorylation targets $\beta$-catenin for ubiquitin-mediated degradation. Following ligand binding and complexing with LRP, the inhibition of GSK-3 $\beta$ results in a stabilised $\beta$-catenin, which leads to $\beta$-catenin accumulation in the cytoplasm. $\beta$-catenin is then translocated into the nucleus and acts as a co-transcriptional activator of T-cell factor and lymphoid enhancer factor that regulate downstream target gene expression (18).

The present study used different concentrations of Wnt1 to intervene in cell proliferation in a dose-dependent manner. When the concentration of Wntl exceeded $20 \mu \mathrm{g} / 1$, cell proliferation was more apparent. Furthermore, we used Wnt1 to intervene with HEPF cells. The results demonstrated that the mRNA and protein expression of $\alpha$-SMA, vimentin and collagen I increased with corresponding Wnt1 in a dose-dependent manner. $\alpha$-SMA in progressive lesions of IPF reflected the transition of fibroblasts to myofibroblasts $(4,19,20)$. Vimentin was a key molecule involved in the post-transcriptional regulation of collagen expression (21). The results demonstrated that Wntl activated myofibroblasts, as well as synthesised and deposited a collagenrich ECM. The present study demonstrated that Wnt1 is able to activate $\beta$-catenin-mediated signalling.

The model of BLM-induced lung injury has been extensively used to investigate potential pathways in the pathogenesis of pulmonary fibrosis $(22,23)$. Our previous studies in BLM-induced pulmonary fibrosis in mice demonstrated that alveolar epithelial injury is severe and $\beta$-catenin expression increases on day 7.

On day 7 of BALF in a BLM mouse model, it was demonstrated that increases in the mRNA and protein expression of $\alpha$-SMA vimentin and collagen I were positively correlated with $\beta$-catenin expression. HEPF cells were infected with a lentivirus containing $\beta$-catenin shRNA, which knocked down the $\beta$-catenin gene and then HEPF cells were cultured with the pulmonary lavage fluid. The present study revealed that the mRNA and protein expression of $\alpha$-SMA, vimentin and collagen I did not significantly increase. The expression of the Wnt ligands and $\beta$-catenin was not measured in the pulmonary lavage fluid from the mouse in the BLM model by ELISA. A possible mechanism may be that in response to injury induced by BLM to the lung epithelium, lung repair mechanisms are initiated immediately. These mechanisms trigger an acute inflammatory response that results in the release of a wide variety of cytokines, in immune cell recruitment and activation of the Wnt signalling pathway. The Wnt family proteins are released by the injured epithelial cells and endothelial cells (11) to the surrounding tissues and shed into the BALF. When BALF was used to culture HEPF cells, it caused $\mathrm{Wnt} / \beta$-catenin signalling activation, even in the absence of the initial injury factors. TGF- $\beta$ is assumed to be a major mediator of fibrosis progression (24). A number of studies demonstrated that $\mathrm{Wnt} / \beta$-catenin signalling is able to upregulate the expression of TGF- $\beta(25,26)$ and TGF- $\beta 1$ can promote $\beta$-catenin signalling (27-31). Crosstalk exists between the Wnt/ $\beta$-catenin pathway and TGF- $\beta$ signalling. In BLM-induced mice, TGF- $\beta$ protein levels in BALF were significantly increased (32-34). We assumed that the BALF obtained from BLM-induced pulmonary fibrosis in a mouse model contained TGF- $\beta$ that activated the Wnt signalling pathway through crosstalk with the Wnt/ $\beta$-catenin pathway.

BALF from the pulmonary fibrosis mouse model contains interleukin (IL)-1 $\alpha$, TNF- $\alpha$, IL-6 (32) and connective tissue growth factor (35). Previous studies demonstrated that the proinflammatory cytokine IL- $1 \beta$ is one of the most upregulated genes in primary murine alveolar epithelial type II cells following Wnt3a treatment (36). Injury to the epithelium initiates the $\mathrm{Wnt} / \beta$-catenin signalling pathway to induce proinflammatory cytokine IL release. Otherwise, Wnt signalling may be triggered by proinflammatory cytokines, including IL- $1 \alpha$, TNF- $\alpha$ and IL- 6 to induce a profibrotic cascade. This profibrotic cascade may result in fibroblast expansion and progressive fibrosis reminiscent of an abnormal wound healing, which requires further investigation.

In summary, the results from the present study demonstrated that sustained activation of $\mathrm{Wnt} 1 / \beta$-catenin signalling increases the number of myofibroblasts in pulmonary fibrosis and promotes fibroblasts to change into myofibroblasts upon tissue injury or inflammation. Furthermore, these results also demonstrated that the activation of a biological repair response and persistence at the injury site is a key factor in the formation of pulmonary fibrosis. The Wnt $1 / \beta$-catenin signalling pathway is important in the formation of fibrotic disease in lung injury and may provide opportunities for treatment and intervention in IPF.

\section{Acknowledgements}

This study was supported by grants from the Scientific Research Project of Ministry of Public Health (no. wkj2006-2-026) and funds from Shanghai Science and Technology Development (no. 10ZR1422600).

\section{References}

1. Chilosi M, Zamò A, Doglioni C, et al: Migratory marker expression in fibroblast foci of idiopathic pulmonary fibrosis. Respir Res 7: 95, 2006.

2. Gross TJ and Hunninghake GW: Idiopathic pulmonary fibrosis. N Engl J Med 345: 517-525, 2001.

3. Katzenstein AL, Zisman DA, Litzky LA, Nguyen BT and Kotloff RM: Usual interstitial pneumonia: histologic study of biopsy and explant specimens. Am J Surg Pahol 26: 1567-1577, 2002 .

4. Scotton CJ and Chambers RC: Molecular targets in pulmonary fibrosis: the myofibroblast in focus. Chest 132: 1311-1321, 2007.

5. Meltzer EB and Noble PW: Idiopathic pulmonary fibrosis. Orphanet J Rare Dis 3: 8, 2008.

6. Selman M, King TE and Pardo A: Idiopathic pulmonary fibrosis: prevailing and evolving hypotheses about its pathogenesis and implications for therapy. Ann Intern Med 134: 136-151, 2001

7. Horowitz JC and Thannickal VJ: Epithelial-mesenchymal interactions in pulmonary fibrosis. Semin Respir Crit Care Med 27: 600-612, 2006.

8. Selman M and Pardo A: Idiopathic pulmonary fibrosis: an epithelial/fibroblastic cross-talk disorder. Respir Res 3: 3, 2002. 
9. Chilosi M, Poletti V, Zamò A, et al: Aberrant Wnt/beta-catenin pathway activation in idiopathic pulmonary fibrosis. Am J Pathol 162: 1495-1502, 2003.

10. Guo Y, Xiao L, Sun L and Liu F: Wnt/beta-catenin signaling: a promising new target for fibrosis diseases. Physiol Res 61 : 337-346, 2012.

11. Königshoff M, Balsara N, Pfaff EM, et al: Functional Wnt signaling is increased in idiopathic pulmonary fibrosis. PLoS One 3: e2142, 2008.

12. Lawson WE, Polosukhin VV, Stathopoulos GT, et al: Increased and prolonged pulmonary fibrosis in surfactant protein $\mathrm{C}$-deficient mice following intratracheal bleomycin. Am J Pathol 167: 1267-1277, 2005.

13. Jiang D, Liang J, Campanella GS, et al: Inhibition of pulmonary fibrosis in mice by CXCL10 requires glycosaminoglycan binding and syndecan-4. J Clin Invest 120: 2049-2057, 2010.

14. Jiang D, Liang J, Hodge J, et al: Regulation of pulmonary fibrosis by chemokine receptor CXCR3. J Clin Invest 114: 291-299, 2004.

15. Meuten T, Hickey A, Franklin K, et al: WNT7B in fibroblastic foci of idiopathic pulmonary fibrosis. Respir Res 13: 62, 2012.

16. Chen S, McLean S, Carter DE and Leask A: The gene expression profile induced by Wnt 3a in NIH 3T3 fibroblasts. J Cell Commun Signal 1: 175-183, 2007.

17. van der Velden JL, Guala AS, Leggett SE, Sluimer J, Badura EC and Janssen-Heininger YM: Induction of a mesenchymal expression program in lung epithelial cells by wingless protein $(\mathrm{Wnt}) / \beta$-catenin requires the presence of c-Jun N-terminal kinase-1 (JNK1). Am J Respir Cell Mol Biol 47: 306-314, 2012.

18. Moon RT, Kohn AD, De Ferrari GV and Kaykas A: WNT and $\beta$-catenin signalling: Diseases and therapies. Nat Rev Genet 5: 691-701, 2004.

19. Broekelmann TJ, Limper AH, Colby TV and McDonald JA: Transforming growth factor beta 1 is present at sites of extracellular matrix gene expression in human pulmonary fibrosis. Proc Natl Acad Sci USA 88: 6642-6646, 1991.

20. Salazar KD, Lankford SM and Brody AR: Mesenchymal stem cells produce Wnt isoforms and TGF-betal that mediate proliferation and procollagen expression by lung fibroblasts. Am J Physiol Lung Cell Mol Physiol 297: L1002-L1011, 2009.

21. Challa AA and Stefanovic B: A novel role of vimentin filaments: binding and stabilization of collagen mRNAs. Mol Cell Biol 31: 3773-3789, 2011.

22. Moeller A, Ask K, Warburton D, Gauldie J and Kolb M: The bleomycin animal model: a useful tool to investigate treatment options for idiopathic pulmonary fibrosis? Int J Biochem Cell Biol 40: 362-382, 2008 .
23. Moore BB and Hogaboam CM: Murine models of pulmonary fibrosis. Am J Physiol Lung Cell Mol Physiol 294: L152-L160, 2008.

24. Biernacka A, Dobaczewski $M$ and Frangogiannis NG: TGF- $\beta$ signaling in fibrosis. Growth Factors 29: 196-202, 2011.

25. Carre AL, James AW, MacLeod L, et al: Interaction of wingless protein (Wnt), transforming growth factor-betal, and hyaluronan production in fetal and postnatal fibroblasts. Plast Reconstr Surg 125: 74-88, 2010.

26. Cheon SS, Wei Q, Gurung A, et al: Beta-catenin regulates wound size and mediates the effect of TGF-beta in cutaneous healing. FASEB J 20: 692-701, 2006.

27. Sato M: Upregulation of the Wnt/beta-catenin pathway induced by transforming growth factor-beta in hypertrophic scars and keloids. Acta Derm Venereol 86: 300-307, 2006.

28. Satterwhite DJ and Neufeld KL: TGF-beta targets the Wnt pathway components, APC and beta-catenin, as Mv1Lu cells undergo cell cycle arrest. Cell Cycle 3: 1069-1073, 2004.

29. Cheon SS, Nadesan P, Poon R and Alman BA: Growth factors regulate beta-catenin-mediated TCF-dependent transcriptional activation in fibroblasts during the proliferative phase of wound healing. Exp Cell Res 293: 267-274, 2004.

30. Ulsamer A, Wei Y, Kim KK, et al: Axin pathway activity regulates in vivo pY654- $\beta$-catenin accumulation and pulmonary fibrosis. J Biol Chem 287: 5164-5172, 2012.

31. Zhou B, Liu Y, Kahn M, et al: Interactions between $\beta$-catenin and transforming growth factor- $\beta$ signaling pathways mediate epithelial-mesenchymal transition and are dependent on the transcriptional co-activator cAMP-response element-binding protein (CREB)-binding protein (CBP). J Biol Chem 287: 7026-7038, 2012.

32. Gurujeyalakshmi G, Wang Y and Giri SN: Taurine and niacin block lung injury and fibrosis by down-regulating bleomycin-induced activation of transcription nuclear factor-kappaB in mice. J Pharmacol Exp Ther 293: 82-90, 2000.

33. Izumo T, Kondo M and Nagai A: Effects of a leukotriene B4 receptor antagonist on bleomycin-induced pulmonary fibrosis. Eur Respir J 34: 1444-1451, 2009.

34. Robb WB, Condron C, Moriarty M, Walsh TN and Bouchier-Hayes DJ: Taurine attenuates radiation-induced lung fibrosis in C57/B16 fibrosis prone mice. Ir J Med Sci 179: 99-105, 2010.

35. Jiang C, Huang H, Liu J, Wang Y, Lu Z and Xu Z: Fasudil, a rho-kinase inhibitor, attenuates bleomycin-induced pulmonary fibrosis in mice. Int J Mol Sci 13: 8293-8307, 2012.

36. Aumiller V, Balsara N, Wilhelm J, Günther A and Königshoff M: Wnt $\beta$-catenin signaling induces IL- $1 \beta$ expression by alveolar epithelial cells in pulmonary fibrosis. Am J Respir Cell Mol Biol 49: 96-104, 2013. 